\title{
Evaluation of results of minimally invasive per cutaneous surgeries in management of calcaneal fractures
}

\author{
Kushal Nikhil Parikh*, Nirav Moradiya, Shalin Shah, Ankit Khodifad
}

Department of Orthopaedics, Surat Municipal Institute of Medical Education and Research, Gujarat, India

Received: 30 November 2018

Revised: 19 December 2018

Accepted: 20 December 2018

\section{*Correspondence: \\ Dr. Kushal Nikhil Parikh, \\ E-mail: kushalparikh@yahoo.com}

Copyright: (c) the author(s), publisher and licensee Medip Academy. This is an open-access article distributed under the terms of the Creative Commons Attribution Non-Commercial License, which permits unrestricted non-commercial use, distribution, and reproduction in any medium, provided the original work is properly cited.

\begin{abstract}
Background: To analyze the outcome percutaneous surgeries in fractures of the calcaneum.

Methods: 20 patients admitted in a tertiary care center in Ahmedabad were followed up from admission to until 2 years post operatively and functional outcomes in them following operative intervention were analyzed using AOFAS and Maryland scoring system.

Results: Majority of patients have excellent or good outcome following percutaneous surgery in fractures of the calcaneum. The results were evaluated for 22 people with intraarticular calcaneum fractures using the Maryland foot score and AOFAS score. The mean AOFAS score was 86. There were 6 excellent, 12 good and 4 fair results.

Conclusions: Percutaneous fixation in fractures of the calcaneum is a middle path in treatment of calcaneum fracture having the benefit of better reduction of ORIF plating and lesser soft tissue injury or chances of infection of conservative management.
\end{abstract}

Keywords: Calcaneum, ST pin, Percutaneous fixation calcaneum, Intraarticular calcaneum

\section{INTRODUCTION}

Calcaneum fractures consist of a majority (60\%) all tarsal fractures. Most commonly they are following an incident of fall from height (Figure 1). ${ }^{1}$ The ideal treatment for this fracture is still debatable, where conservative treatment used to be the treatment of choice in the past, open reduction plating has become the treatment of choice these days, both having their own brickbats and benefits. $^{2-4}$

Open reduction though returns the anatomical reduction, technical problems, infection and rarely the need for amputation, prejudiced surgeons against operative treatment. Compared to open procedures, minimally invasive procedures offer the prospect of good reduction with fewer complications.
The purpose of this study is to review our experience of such a minimally invasive reduction and Steinmann pin fracture fixation in the treatment of intraarticular fracture of the calcaneum.
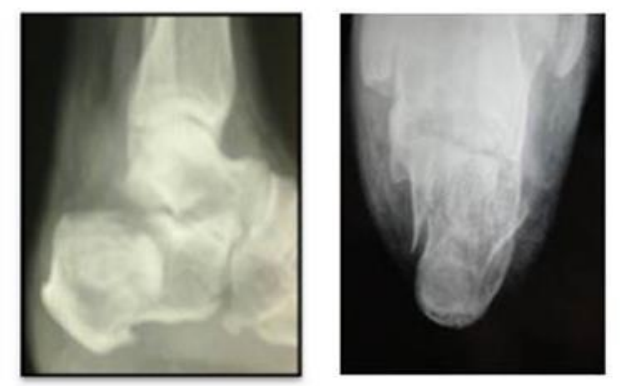

Figure 1: Intraarticular displaced calcaneum fracture: lateral and axial view. 


\section{METHODS}

This is an observational study carried out over a period of two years at V.S. Hospital, Ahmedabad, Gujarat from 2010 to 2012. Appropriate institutional ethical committee approval was taken before carrying out the study. A total of 20 patients with 22 (two bilateral) displaced calcaneal fractures were studied. Inclusion criteria were skeletally mature patients of both sexes; closed displaced calcaneal fracture; no neurological or vascular deficit; patients giving informed written consent. Exclusion criteria were any pathological fracture; open fracture; patient with any form of neurological involvement or distal vascular deficit; patient not giving consent. Included patients were treated by closed reduction and internal fixation with percutaneous fixation by Essex Lopresti technique.

\section{Procedure of the percutaneous minimally invasive technique}

All procedures were done in well-equipped orthopedics operation theatre. Surgeries were performed under general or spinal anesthesia. Patient was kept on simple table in lateral position with a tourniquet. Appropriate painting and draping were done using strict aseptic precautions.

\section{Operative technique}

The aim is direct reduction of the displaced fragments to articular surface reconstruction under Image Intensifier control with indirect reduction of the general alignment of the calcaneum. The patient is placed in a lateral decubitus position on a radiolucent operating table with the injured limb uppermost. IITV is introduced and good lateral, axial and Broden's view are obtained before operating.

\section{Step 1}

Pin introduction, disimpaction and correction of valgus/varus malalignment to sustenaculum tali. This is achieved with a $4.5 \mathrm{~mm}$ ST pin.

\section{Step 2}

Reduction of the articular surface under image-intensifier control. In joint depression type, entry is made through the sole while in tongue type entry is made superiorly beside the tendo-achilles. In complex fractures both techniques are combined. Once reduction is confirmed with the image intensifier, the fracture is held with a 2 $\mathrm{mm} \mathrm{K}$-wire. An additional $2 \mathrm{~mm} \mathrm{~K}$-wire is usually placed parallel to the pin, medial to the tendo-achilles.

\section{Step 3}

Compression of the heel in order to impact the lateral wall.
Finally, the pins are cut flush with the skin and a sterile, bulky dressing is applied. If needed $4 \mathrm{~mm}$ cannulated cancellous screw were inserted to maintain reduction.

\section{Postoperative management}

The patients were started range of movement exercises of the ankle and subtalar joint on the second post-operative day and allowed to walk without bearing weight on the affected limb. Most patients with unilateral fractures were discharged after three to four days.

The ST pins were removed after a mean of 8 weeks ( 8 to 10), depending on the type of fracture and the degree of union, and partial weight-bearing was allowed with full weight-bearing at a mean of 13 weeks.

The present study included 22 cases of calcaneal fractures treated by Essex-Lopresti's technique of closed reduction with percutaneous minimally invasive surgery using percutaneuos screws, steinmann pins/K-wires. The basic aim of the surgery was to achieve as near anatomical realignment and optimum subtalar joint congruity as possible.

Assessment of the final result of the study was made using Maryland Foot-score and American Orthopaedic Foot and Ankle society score. The results were statistically analysed using arithmetic mean At follow up, Bohler's tuber joint angle was measured in normal foot, and affected foot at radiological union and ratio was calculated. A watch for development of complications was constantly made.

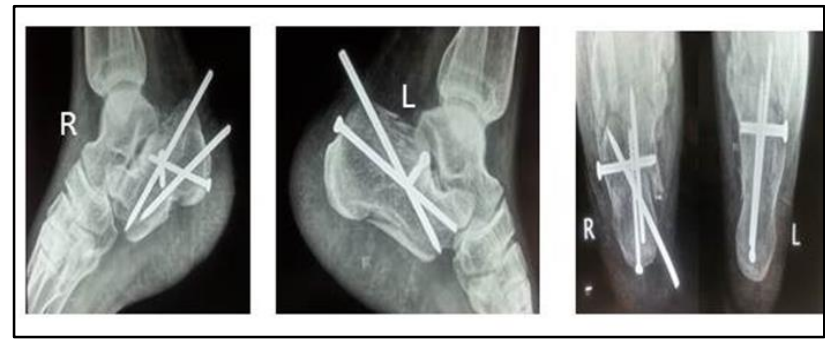

Figure 2: Postoperative intra-articular calcaneum fracture managed with $\mathrm{CC}$ screw and ST pin fixation.

\section{RESULTS}

In this series of 20 patients, the age distribution is from youngest-around 20 to oldest 49. Maximum age incidence is from $25-34$ (81\%- 18 patients) the mean age being 30 . There is male predominance of the patients in our study with 18 patients being males (90\%) and 2 patients being females (10\%). Among the 22 fractures, 9 had right side $(40.91 \%)$ and 11 were left side $(50 \%)$ and 2 were bilateral $(9.09 \%)$.

In this series fall from different ground level comprises the major mode of Injuries accounting 16 patients 
(72.73\%) (Table 1). Majority of the fractures were isolated fractures not involving any other part of the body $(77.27 \%)$. Injury to the spine was present in 2 patients (Table 2).

Table 1: Mode of injury.

\begin{tabular}{|lll|}
\hline Mode of injury & No. of patients & $\begin{array}{l}\text { Percentage } \\
(\%)\end{array}$ \\
\hline Fall from height & 16 & 72.73 \\
\hline Slipped & 2 & 09.09 \\
\hline RTA & 4 & 18.18 \\
\hline Total & 22 & 100 \\
\hline
\end{tabular}

Table 2: Associated injuries.

\begin{tabular}{|lll|}
\hline $\begin{array}{l}\text { Associated } \\
\text { injury }\end{array}$ & $\begin{array}{l}\text { No. of } \\
\text { patients }\end{array}$ & Percentage $(\%)$ \\
\hline None & 17 & 77.27 \\
\hline Spine & 2 & 09.09 \\
\hline Others & 3 & 13.64 \\
\hline Total & 20 & 100 \\
\hline
\end{tabular}

In this series 18 cases $(81.81 \%)$ were intra-articular with $11(50 \%)$ were Joint depressing and $7(31.81 \%)$ were tongue type and $4(18.19 \%)$ were of extra-articular variety of tuberosity or sustentaculum type.
In this series of patients operated by minimally invasive percutaneous technique $16(72.73 \%)$ were treated through screws \pm ST pins and 6 patients $(27.27 \%)$ with ST pin \pm $\mathrm{K}$ wires (Table 3 ). The average duration after the injury when patient was operated is 2 days in our study (Table 4). Earlier operation does not have any correlation with incidence of infection.

Table 3: Operative intervention.

\begin{tabular}{|lll|}
\hline $\begin{array}{l}\text { Type of } \\
\text { operation }\end{array}$ & $\begin{array}{l}\text { No. of } \\
\text { patients }\end{array}$ & $\begin{array}{l}\text { Percentage } \\
(\%)\end{array}$ \\
\hline Screws \pm ST pins & 16 & 72.73 \\
\hline ST pin \pm K wires & 6 & 27.27 \\
\hline Total & 22 & 100 \\
\hline
\end{tabular}

Table 4: Time after injury when operated.

\begin{tabular}{|lll|}
\hline $\begin{array}{l}\text { Time after which } \\
\text { operated (days) }\end{array}$ & $\begin{array}{l}\text { No. of } \\
\text { patients }\end{array}$ & $\begin{array}{l}\text { Percentage } \\
(\%)\end{array}$ \\
\hline $\mathbf{0 1}$ & 7 & 31.82 \\
\hline $\mathbf{0 2}$ & 12 & 54.55 \\
\hline $\mathbf{0 3}$ & 3 & 13.63 \\
\hline
\end{tabular}

Table 5: Clinical and radiological outcome.

\begin{tabular}{|c|c|c|c|c|c|}
\hline Parameters & Joint depressing & Tongue type & Extra-articular & Total & Percentage $(\%)$ \\
\hline \multicolumn{6}{|l|}{ Bohler Angle } \\
\hline$<20$ degree & 2 & 2 & 1 & 4 & 18.2 \\
\hline$>20$ degree & 9 & 5 & 3 & 18 & 81.8 \\
\hline \multicolumn{6}{|l|}{ Impalnts used } \\
\hline Screws \pm ST pins & 9 & 6 & 1 & 16 & 72.73 \\
\hline $\mathrm{ST}$ pin $\pm \mathrm{K}$ wires & 2 & 1 & 3 & 6 & 27.27 \\
\hline \multicolumn{6}{|l|}{ Complications } \\
\hline Broadening of heel & 5 & 1 & 2 & 8 & 36.36 \\
\hline Loss of height & 5 & 2 & 0 & 7 & 31.81 \\
\hline Varus & 2 & 0 & 1 & 3 & 13.63 \\
\hline Restricted movement & 3 & 1 & 0 & 4 & 18.18 \\
\hline Wound complication & 1 & 0 & 1 & 2 & 09.09 \\
\hline Removal of implant & 0 & 1 & 0 & 1 & 04.54 \\
\hline Mal-union & 1 & 0 & 0 & 1 & 04.54 \\
\hline Subtalar arthritis & 1 & 1 & 0 & 2 & 09.09 \\
\hline Change of job & 3 & 2 & 1 & 6 & 27.27 \\
\hline Limp & 1 & 1 & 0 & 2 & 09.09 \\
\hline Pain & 3 & 2 & 1 & 6 & 27.27 \\
\hline Flat foot & 1 & 0 & 0 & 1 & 04.54 \\
\hline \multicolumn{6}{|l|}{ Results } \\
\hline Excellent & 3 & 2 & 2 & 7 & 31.82 \\
\hline Good & 5 & 5 & 2 & 12 & 54.55 \\
\hline Fair & 3 & 0 & 0 & 3 & 13.63 \\
\hline Poor & 0 & 0 & 0 & 0 & 00 \\
\hline Total & 11 & 7 & 4 & 22 & 100 \\
\hline
\end{tabular}


In this series, there were 11 joint depression type fractures. Their average MFS score was 86.2 and AOFAS score 84.5 . Of these, 3 had excellent outcome, 5 had good and 3 had fair results. There were 7 tongue type fractures, whose mean MFS score was 85.1 and AOFAS score was 88.7. Of these, 2 had excellent, and 5 had good outcome. There were 4 extraarticular fractures whose mean MFS score and AOFAS score was 91 and 92.3 respectively. Of these, 2 had excellent and 2 had good outcome.

There was radiological union in $21(95.45 \%)$ patients. In most $16(72.73 \%)$ cases duration of incapability was 4 months. Loss of reduction was seen in $1(4.54 \%)$. Pain remained in $3(13.64 \%)$ cases. Two $(9.09 \%)$ cases recorded infection at operated site with $4(81.82 \%)$ had difficulty in wearing shoes on follow ups. There was subtalar joint arthritis in $2(9.09 \%)$ cases and flat foot in 1 $(4.54 \%)$ case. Table 5 tabulates the clincal and radiological outcome in our study correlating with the fracture type.

In this series the Gissane's angle was restored to $<130$ degrees in 21 out of 24 cases. Out of the 3 cases which did not reach $<130$ of Gissane's, 2 had fair outcome while the third has good. The Bohler's angle was restored to within the normal range of 20-40 degrees in or study in 20 out of 24 cases. In the 4 cases where it was not achieved, 2 had fair outcome whereas 1 had Good and 1 had excellent outcome.

In this series, 16 patients $(72.73 \%)$ were able pursue their routine work and around 4 patients $(18.18 \%)$ needed to change the job and around 2 patients $(9.09 \%)$ yet to resume.

\section{DISCUSSION}

Calcaneus fractures are usually affecting young males with economically active age group which contributes to significant socio-economical loss.

In present study, by observing the stratified distribution of the patients, it was shown that $90.91 \%$ were within 20 to 40 years old, and only $09.09 \%$ were old aged, goes with the statement that this condition affects individuals who are working for economic reasons. Nambiar noted that $56 \%$ of his patients were in the $3 \mathrm{rd}$ to 4th decade of life, Parmar noticed age range between 16-64 with mean age 50.9 years and Buckley noted that in his study the maximum age incidence was between $30-39$ years $(60 \%)$ with age range between 15-68 years. $^{4-6}$

In this present study 20 patients were males (90.91\%) and 2 patients were females $(9.09 \%)$, showing male preponderance (M:F- 9:1). Parmar noted male to female ratio of 2.3:1, Pozo 4:1, Nambiar 10:1 and Paley $6: 1 .^{4,5,7,8}$ In our society, male population works for earning to serve the family.
The most common mode of injury of calcaneus intrajoint fractures, as reported by literature, is the fall from different ground levels, which was confirmed by this study, where this, kind of fall accounted for $72.73 \%$ of the fractures. ${ }^{9-11}$

Due to the axial mechanism of trauma, existence of associated injuries is possible. Various authors report this fact occurring in percentages ranging 8.5 to $46 \%$ of patients. ${ }^{11}$ In this study, other injuries were found in $22.72 \%$ of the patients. Hildebrand reported associated spine fractures in $10 \%$, Buckley reported $15 \%$ and Nambiar reported $21 \%$ associated spine injuries whereas in this study spine injuries accounted $09.09 \%$ of cases. ${ }^{4,6,12}$

In accordance to Essex-Lopresti's classification, intraarticular fractures may be tongue-type or joint depression-type. $^{13}$ In most of the case series, joint depression-type fractures are the most prevalent, accounting for $61 \%$ of intra-joint fractures. ${ }^{14-16}$ In this study, we found $50 \%$ of joint depression-type fractures and $31.81 \%$ tongue-type fractures. The kind of fracture were related to outcome and return to work.

For the surgical treatment, there is a consensus of waiting sometime between trauma and surgery, ranging from immediate to 5 days for percutaneous surgeries so that edema could be reduced and for preventing blisters to be formed, except in open fractures, which should receive immediate surgical care. In this study, the time interval between trauma and surgery for all the fractures was, in average, 1 to 3 days.

Patients treated using percutaneous technique could be operated on as soon as possible after injury. Levine and Helfet, in their series of intra-articular fractures of the calcaneum treated with a minimally-invasive technique, were surprised that subtalar movement was almost completely preserved despite an articular surface reconstruction described as 'nearly anatomical'. ${ }^{17}$ Thermann et al advised minimallyinvasive fixation for cases with severe soft-tissue contusion, compound and Sanders type-IV fractures, and in multiply-injured patients. ${ }^{18}$ In present case study all patients were treated by minimally invasive percutaneous surgeries

The Bohler's angle, considered as normal within measurements ranging from $20^{\circ}$ to $40^{\circ}$, is used for indication changes on the posterior joint facet and for qualifying fracture resolution. Loucks and Buckley performed a prospective and randomized study to evaluate the Bohler's angle and they observed that surgical treatment improved angle graduation as well as the functional status. The stated that fractures with a Bohler's angle markedly reduced at the immediate post-trauma period provided bad outcomes and they suggested that the high energy of trauma produces angle flattening, with a more extensive bone and soft 
parts injury. In this study, variations between 10 and 40 degree were found. The value of this angle showed a correlation with the quality of outcome. This study shows that 20 of the reductions with an angle above $20^{\circ}$ presented good and excellent outcomes. We have compared our analysis with Paley who did a similar analysis and has similar conclusions. ${ }^{10}$

In the evaluation of the results by AOFAS and Maryland foot score scale, we found the results in various clinical studies ranging from $65 \%$ to $80 \%$ of excellent results for percutaneous surgeries in fracture of calcaneus. In our study, outcomes were considered as good and excellent in $86.36 \%$. O'Farrel et al reported that $66.66 \%$ of the patients submitted to surgery returned to work, while in our study $20(90.91 \%)$ were managed to return to work of which $16(72.73 \%)$ returned to original work while $4(18.18 \%)$ required a change in job. ${ }^{19}$

No major complications are associated with per cutaneous approach. In early complications our study shows $2(9.09 \%)$ infection with wound complication which were managed conservatively. In the Late complications our study marks loss of reduction in 1 (4.54\%) case, mal-union in $1(4.54 \%)$ case, subtalar joint arthritis in $2(9.09 \%)$ case and flat foot in 1 $(4.54 \%)$ case. This is comparable to Nambiar (13\%), Poupa (17\%) and Tornetta $(10 \%)$ who had reported subtalar arthritis in their series. ${ }^{4,20,21}$

$33 \%$ of all calcaneal fractures are extra-articular. These percentages were calculated before the description of various types of avulsion fractures and might have been underscoring the number of extra-articular calcaneal fractures. $^{22,23}$ In our study extra-articular fractures contributed $18.19 \%$ comprising of tuberosity (13.63\%) and sustentaculum (4.54\%) types. Patients with an extraarticular calcaneal fracture were significantly younger but male-female ratio was negligible. This is explained largely by the divergence in trauma-mechanism. The intra-articular calcaneal fractures occur frequently as work-related high-energy accidents and the extra-articular mainly as distortion injuries. ${ }^{23,24}$

\section{CONCLUSION}

The percutaneous fixation method requires neither a specialist nor any expensive technical equipment but also due to its undemanding nature, short hospitalization and less complication it is very acceptable by patients. Application of percutaneous reduction and fixation methods to all types of calcaneal fractures carries a considerable risk to inadequate joint reconstruction and re-dislocation. Also lower Bohler's angle has significant association with unsatisfactory result. Intra-articular fractures in patients at increased risk from a formal open reduction can be treated safely with a minimally-invasive technique. Tongue-type fractures can be successfully treated using a minimally-invasive technique while joint depression fractures are generally difficult to reduce. In extra-articular fractures treated with surgery the return to daily routine activities is good compared to the conservatively managed extra-articular fracture.

Funding: No funding sources

Conflict of interest: None declared

Ethical approval: The study was approved by the institutional ethics committee

\section{REFERENCES}

1. Slatis PK, Kiviluoto O, Santavirta S. Fractures of the calcaneum. J Trauma. 1979;19:939-44.

2. Aaron DA. Intraarticular fractures of the calcaneum. J Bone Joint Surg. 1974;56:567.

3. Schofield RO. Fractures of the OsCalcis. J Bone Joint Surg. 1936;18:566-80.

4. Nambiar MR, Umesh SN, Kamath KR. Percutaneous pin fixation of calcaneal fractures. J OrthopAssoc South Ind. 2004;1:64-7.

5. Parmar HV, Triffitt PD, Gregg PJ. Intra-articular fractures of the calcaneum treated operatively or conservatively. A prospective study. J Bone Joint Surg. 1993;75(6):932-7.

6. Buckley R, Tough S, McCormack R, Pate G. Operative compared with non-operative treatment of displaced intra-articular calcaneum fractures. J Bone Joint Surg. 1996;78:119-23.

7. Pozo JL, Kirwan EO, Jackson AM. The long-term results of conservative management of severely displaced fractures of the calcaneus. J Bone Joint Surg. 1984;66(3):386-90.

8. Paley D, Hall H. Intra-articular fractures of the calcaneum: A critical analysis of results and prognostic factors. J Bone Joint Surg. 1993;75(3):342-54.

9. Sanders. Displaced I/A fractures of the calcaneus. JBJS Am. 2000;82:225-50.

10. Aarvey EJ, Grujic L, Early JS, Benirschke SK, Sangeorzan BJ. Morbidity associated with ORIF of intra-articular calcaneus fractures using lateral approach. Foot Ankle Int. 2001;22:868-73.

11. Koberle G, Oliveira AC, Sandoval PS. Fraturas intra-articulares do calcaneo. Rev Bras Ortop. 1996;31:477-80.

12. Hildebrand KA, Buckley RE. Functional outcome measures after displaced intra-articular calcaneum fractures. J Bone Joint Surg. 1996;78:119-23.

13. Eastwood DM, Gregg PJ, Atkins RM. Intra-articular fractures of the calcaneum. Part I: Pathological anatomy and classification. J Bone Joint Surg. 1993;75(2):183-8.

14. Moraes Filho DC, Provenzano E, Mattos JR, Batista LC, Galbiatti JA, Ferreira JCD, et al. Avaliacaopreliminar do tratamentocirurgico de fraturasinta-articulares do calcaneo. Rev Bras Ortop. 1998;3:511-8.

15. Leung KS, Yuen KM, Chan WS. Operative treatment of displaced intra-articular fractures of the 
calcaneum: medium-term results. JBJS $\mathrm{Br}$. 1993;75:196-201.

16. Kennedy JG, Jan WM McGuinness AJ, Barry K, Curtin J, Cashman WF et al. An outcomes assessment of intra-articular calcaneal fractures, using patient and physicians assessment profiles. Injury. 2003;34:932-6.

17. Levine DS, Helfet DL. An introduction to the minimally invasive osteosynthesis of intra-articular calcaneal fractures. Injury. 2001;32:51-4.

18. Thermann H, Krettek C, Hüfner T, Schratt HE, Albrecht K, Tscherne H. Management of Calcaneal Fractures in Adults: Conservative Versus Operative Treatment. Clin Orthop Rel Res. 1998;353:107-24.

19. O'Farrell DA, O'Byrne JM, McCabe JP, Stephens MM. Fractures of the os calcis: improved results with internal fixation. Injury. 1993;24(4):263-5.

20. Poupa J, Pribyl J. Surgical results of the Essex Lopresti method in calcaneum fractures. Acta chirurgiae orthopaedicae et traumatologiae Cechoslovaca. 1971;38(1):23-5

21. Tornetta III P. Percutaneous treatment of calcaneal fractures. Clinl Orthop Related Res. 2000;375:91-6.

22. Brijs S, Brijs A. Calcaneal avulsion: a frequent traumatic foot lesion. InRöFo-Fortschritte auf dem Gebiet der Röntgenstrahlen und der bildgebenden Verfahren 1992;156(5):495-6.

23. Norfray JF, Rogers LF, Adamo GP, Groves HC, Heiser WJ. Common calcaneal avulsion fracture. American J Roentgenol. 1980;134(1):119-23.

24. Degan TJ, Morrey BF, Braun DP. Surgical excision for anterior-process fractures of the calcaneus. J Bone Joint Surg. 1982;64(4):519-24.

Cite this article as: Parikh KN, Moradiya N, Shah S, Khodifad A. Evaluation of results of minimally invasive per cutaneous surgeries in management of calcaneal fractures. Int J Res Orthop 2019;5:81-6. 